\title{
Efficacy and efficiency of a lean cataract pathway: a comparative study
}

\author{
Ellen Joan van Vliet, ${ }^{1,2}$ Walter Sermeus, ${ }^{1}$ Claudia M van Gaalen, ${ }^{2}$ Johannes C A Sol, ${ }^{2}$ \\ Jan $\mathrm{M} \mathrm{H}$ Vissers $^{3}$
}

${ }^{1}$ School of Public Health, Faculty of Medicine, Catholic University Leuven, Leuven, Belgium ${ }^{2}$ Rotterdam Eye Hospital, Rotterdam, The Netherlands ${ }^{3}$ Institute of Health Policy and Management, Erasmus University Medical Center Rotterdam, Rotterdam, The Netherlands

\section{Correspondence to}

Ms Ellen Joan van Vliet, Rotterdam Eye Hospital, PO Box 70030, Rotterdam 3000LM, The Netherlands:

ellen.vanvliet@oogziekenhuis.nl

Accepted 22 April 2009 Published Online First 22 April 2010

\section{ABSTRACT}

Background The demand for cataract surgery is rising, calling for pathways that have good access and are costeffective. Lean thinking is a management strategy, aimed at improving quality while reducing costs. Lean production processes are designed to identify gaps between expected and actual performance.

Aim To analyse the efficacy and efficiency of a lean cataract pathway.

Methods Lean care delivered to a prospective cohort (616 cataract patients) was compared (1) with traditional care delivered to a historical cohort (591 cataract patients) and (2) with expected lean care in the prospective cohort. To evaluate efficacy, the authors analysed how many patients received care that adhered to the lean pathway's specifications. To evaluate efficiency, the authors analysed how often patients visited the hospital and how many additional patients could access the pathway.

Results In the lean pathway, patient visits decreased by $23 \%$, and access to the cataract pathway increased with $42 \%$. A $40 \%$ decrease in patient visits and a $76 \%$ increase in access could have been realised if healthcare staff would have adhered to the lean pathway's specifications.

Practice implications Lean pathways can realise large improvements, and still have a significant gap between expected and actual care delivery. The challenge for healthcare teams is not to improve care delivery by using lean pathways as opposed to using traditional pathways, but to strive for optimal performance by consistently adhering to the specifications of the lean pathway.

\section{INTRODUCTION}

Cataract, a clouding of the lens of the eye, is the leading cause of treatable blindness in the world. ${ }^{1}$ Cataract surgery is a reasonably safe and successful procedure, and the most frequently performed ophthalmic surgical procedure. ${ }^{2-4}$ The demand for cataract surgery is rising, due to an ageing population and an expanding life expectancy. ${ }^{5}$ This calls for cataract pathways that have good access and are cost-effective. ${ }^{6}$ Because the cataract pathway is a high-volume, low-complex procedure, cataract care is an excellent arena for applying industrial principles, such as lean thinking. 78

Lean thinking, which was originally developed in Japan by Toyota Motor Corporation in 1930, is a management strategy, aimed at improving quality while reducing costs. ${ }^{10}$ Toyota designed their production processes to immediately identify gaps between expected and actual performance. ${ }^{11}$ Service industries, such as healthcare, may benefit from applying lean thinking. ${ }^{12-15}$ However, in contrast with Toyota's robust production processes, care processes often lack reliable mechanisms for coordinating care across departments. ${ }^{16-18}$ This may result in a delivery gap, that is, differences between expected and actual care delivery. ${ }^{19} 20$

Various studies have evaluated the application of lean thinking in healthcare..$^{21-24}$ In these studies, the effect of implementing lean thinking is usually determined by only comparing it with a baseline measurement. However, differences between expected and actual care delivery have not been studied. The aim of this study was to investigate possible delivery gaps of a lean cataract pathway by measuring its efficacy and efficiency. We formulated the following research questions:

1. What is the efficacy of the lean cataract pathway, that is, how many patients received care according to specifications of the lean pathway design?

2. What is the efficiency of the lean cataract pathway, that is, did the implementation of the lean pathway decrease the number of hospital visits per patient and increase access to the pathway?

\section{METHODS}

\section{Study design and patient groups}

We performed a comparative study in the cataract surgery clinic of the Rotterdam Eye Hospital, The Netherlands. We compared a historical cohort of all 591 patients who underwent cataract surgery in October and November 2004, with a prospective cohort of all 616 patients who underwent cataract surgery in February and March 2007. No patients were excluded. Patients in the historical cohort received care in a traditional cataract pathway (figure 1). Their mean age was 70 years $(\mathrm{SD}=11)$; 223 patients were men (37.7\%). Patients in the prospective cohort received care in a lean cataract pathway (figure 1). Their mean age was 70 years $(\mathrm{SD}=11) ; 247$ patients were men $(40.1 \%)$. No statistical differences were found between the two cohorts in age (independent-samples t test, $\mathrm{p}=0.56$ ) or gender $\left(\chi^{2}\right.$ test, $\left.p=0.40\right)$. We did not include patients who underwent cataract surgery in 2005 and 2006, because the lean pathway was gradually introduced between February 2005 and October 2006.

\section{Traditional cataract pathway}

The traditional pathway started with an ophthalmic examination in the outpatient clinic to diagnose cataract (figure 1). The patient then made an extra visit to the hospital for receiving 
Figure 1 Design of traditional cataract pathway (left side), and lean cataract pathway (right side). The expected distribution of 616 patients to traditional or new care alternatives in the lean cataract pathway is presented in the algorithm of the lean pathway. Between square brackets: frequency of hospital visits per patient during the cataract pathway. Between parentheses: amount of time in minutes that ophthalmologists spend per patient on each activity in the lean pathway. Grey blocks: patient not in hospital.

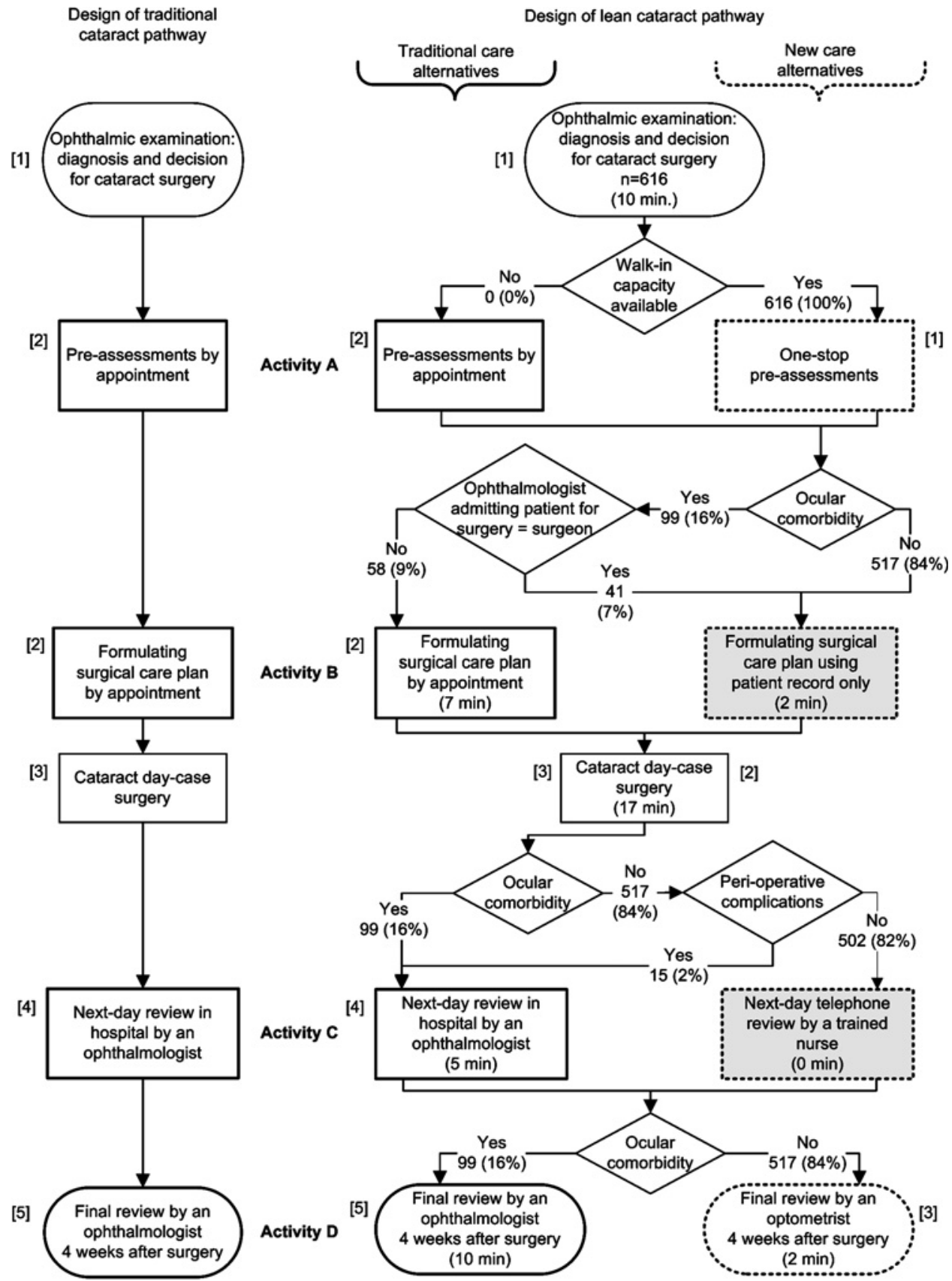

Design of traditional cataract pathway preassessments (eg, nursing anamnesis, health check and biometry) (activity A). This was usually combined with an appointment for an ophthalmic screening (activity B). The surgeon then formulated a surgical care plan to outline details of the surgery. Cataract surgery was performed as a same-day outpatient procedure. The day after surgery, the surgeon examined the patient for any early-postoperative complications (activity C). The pathway ended with a final review 4 weeks after surgery (activity D). The surgeon then determined the refractive error and best-corrected visual acuity. For each patient, the traditional pathway comprised five visits to the hospital.

\section{Lean cataract pathway}

Facing a growing demand for cataract surgery in a competitive environment, The Rotterdam Eye Hospital wanted to increase access and surgical throughput, while decreasing costs and patient visits. For these reasons, they applied lean thinking in their cataract pathway. Ophthalmologists and nurse managers searched for new alternatives in literature and best practices in colleague eye hospitals. They gradually constructed the lean pathway by integrating best practices and streamlining the care process. ${ }^{4} 25-31$

The lean pathway enclosed care alternatives for activity A, B, $\mathrm{C}$ and $\mathrm{D}$ (figure 1). In activity $\mathrm{A}$, preassessments followed the initial ophthalmic examination as a one-stop visit. In activity $B$, formulating the surgical care plan was standardised, enabling surgeons to screen the patient record only, without having to see the patient. In activity $\mathrm{C}$, trained nurses interviewed patients using a protocol checklist during a telephone review. In activity $\mathrm{D}$, optometrists performed the final review. The lean pathway involved for each patient three visits to the hospital when the patient received all new care alternatives.

For the lean pathway, cataract surgeons formulated decision rules (figure 1). Based on these decision rules, patients were allocated to either the lean pathway's traditional care alternatives or the lean pathway's new care alternatives. Nurse 
managers defined service specifications for following-up ophthalmologist's orders. A nurse from the cataract surgery clinic performed the telephone reviews during off-peak moments. Two days per week, an optometrist was scheduled to perform the final reviews after cataract surgery.

To evaluate safety in the lean pathway, a random sample of 274 patient records of patients, undergoing cataract surgery between June 2005 and February 2006, were analysed. No statistical differences were found in the number of postoperative complications ( $\chi^{2}$ test, $\left.p=0.58\right)$ and the number of visits to the Accident and Emergency (A\&E) department ( $\chi^{2}$ test, $p=0.65$ ) between the lean pathway ( $n=152$; seven complications $(4.6 \%)$; eight $A \& E$ visits $(5.3 \%)$ ) and the traditional pathway $(n=122$; four complications (3.3\%); five A\&E visits (4.1\%)).

\section{Data collection}

We consulted the hospital's database to analyse the care patients received in the traditional and lean pathway. All patient's consultations in the outpatient clinic and preassessment clinic, including details on date, care professional and activity, were registered in digital agendas and archived in the hospital's database.

One of the authors (CMvG) analysed all 616 patient records for presence of ocular comorbidity (yes/no); orders for ophthalmic screening to formulate the surgical care plan (by appointment/patient record only), orders for next-day review (in-hospital/telephone/self review); orders for final review (ophthalmologist/optometrist); name of the ophthalmologist admitting the patient for surgery; presence of perioperative complications (yes/no); and the conducted next-day review (inhospital/telephone/self review). To assess inter-rater reliability, one of the other authors (EJvV) analysed $31(5.0 \%)$ randomly selected patient records. In only $2.0 \%$ (5/248 data values), there was a mismatch between data.

Two of the authors (CMvG, EJvV) interviewed four ophthalmologists, two optometrists, three nurses, four managers and six administrative staff employees about their experiences with the lean pathway. We asked them why they did or did not follow the lean pathway design (box 1). Directly after the interview, an interview report was typed based on notes and the author's memory. One week later, the interview report was discussed with the respondent. Four interview reports needed modifications. All modifications involved describing details of how the respondent's tasks were executed. The modified reports were finalised in a third meeting. Data were analysed using content analysis. ${ }^{32}$ Two authors (EJvV, $\mathrm{CMvG}$ ) developed independently from each other a list of categories and discussed these. Together with a third author

Box 1 Topic list used in the interviews of the multidisciplinary care team members $(n=19)$ about their experiences with the lean pathway

1. Can you specify the tasks you execute with regard to the pathway's specifications?

- Ophthalmologists: How do you decide what care alternatives the patient should receive and how do you order these?

- Other: How do you carry out the ophthalmologist's orders?

2. What do you need to adhere to the pathway's specifications?

3. What problems do you encounter that hinder you from adhering to the pathway's specifications?
(WS), they constructed four final categories (eg, resource availability, accuracy of specifications, coordination mechanisms and behaviour), which were used for the interpretation of the quantitative analysis.

\section{Measures of efficacy}

To evaluate efficacy, we analysed how many patients received new care alternatives and how many patients were expected to receive new care alternatives according to the lean pathway design.

To analyse how many patients received one-stop preassessments, we determined for each patient whether preassessments were conducted at the same date of the initial consultation. In the lean pathway, we expected that all patients would receive one-stop preassessments (figure 1).

To analyse how often ophthalmologists formulated the surgical care plan using the patient record only, we determined how many patients did not have a screening appointment registered. In the lean pathway, we expected that ophthalmologists would formulate the surgical care plan using the patient record only for patients without ocular comorbidity and for patients who had the same ophthalmologist admitting them for surgery and performing the surgery (figure 1).

To analyse how many patients received a telephone next-day review, we determined for each patient the type of next-day review that was registered in the patient record. In the lean pathway, we expected that all patients without ocular comorbidity and without a perioperative complication would receive a telephone review (figure 1).

To analyse how many patients received a final review by an optometrist, we determined for each patient whether this review was registered with an optometrist in the hospital's database. In the lean pathway, we expected that all patients without ocular comorbidity would receive an optometrist review (figure 1).

\section{Measures of efficiency}

To evaluate efficiency, we determined how often patients visited the hospital during cataract treatment and how many additional patients accessed the cataract pathway. The rationale for the latter was that, presumably, the lean pathway would free-up ophthalmologists' time, enabling ophthalmologists to treat more patients.

To determine the number of hospital visits per patient, we consulted the hospital's database to analyse how often patients visited the hospital between initial consultation and final review. For each patient, we determined what care alternatives the patient was expected to receive according to the lean pathway design, and how many hospital visits this would take (figure 1).

To analyse how many additional patients accessed the cataract pathway, we calculated how much time ophthalmologists spent on direct care per patient. During consulting hours, 10 min was allocated per patient to diagnose cataract or to conduct the final review (figure 1). In December 2006, we measured how much time ophthalmologists spent on formulating the surgical care plan by appointment $(7 \mathrm{~min}, \mathrm{n}=10)$ or using the patient record only ( $2 \mathrm{~min}, \mathrm{n}=10)$, and on conducting the next-day review ( $5 \mathrm{~min}, \mathrm{n}=10$ ). We used the actual duration of surgery by extracting the end time of surgery from start time in the hospital's database.

To determine how much time an ophthalmologist would spend per patient in the lean pathway, we determined for each patient what care alternatives the ophthalmologist was expected to deliver and enumerated the required amount of 
time. To determine additional access, we calculated how many patients an ophthalmologist could treat in the lean pathway related to the time an ophthalmologist needed to treat one patient in the traditional pathway.

\section{Adherence to the lean pathway design}

To better understand the cause of any gap we might find between actual and expected care delivery, we analysed to what extent the care team adhered to the lean pathway design. First, to analyse an ophthalmologist's adherence to decision rules, we determined for each patient if orders given by the ophthalmologist corresponded with expected care delivery (figure 2, result 1). Second, to analyse the organisation's adherence to service specifications and the ability to follow-up ophthalmologist's orders, we determined for each patient whether actual care delivery corresponded with ophthalmologist's orders (figure 2 , result 2). Finally, to analyse the team's adherence to the lean pathway design, we determined for each patient whether actual care delivery corresponded with expected care delivery (figure 2, result 3).

\section{Statistical analysis}

Differences between the traditional and lean pathway in (A) one-stop preassessments, (B) formulating the surgical care plan using the patient record only, $(\mathrm{C})$ telephone next-day review and (D) final review by an optometrist were analysed with $\chi^{2}$ tests. Differences between actual and expected care delivery in the lean pathway in these four parameters were analysed with McNemar tests.

Differences between the traditional and lean pathway in (1) patient visits, (2) ophthalmologist's time spent per patient and (3) number of patients treated, related to ophthalmologist's time needed to treat one patient in the traditional pathway, were analysed with independent-samples $t$ tests. Differences between actual and expected care delivery in the lean pathway in these three parameters were analysed with paired-samples $t$ tests. A p value of $<0.05$ was considered statistically significant.

\section{RESULTS}

The lean pathway significantly outperformed the traditional pathway (table 1). The number of visits individual patients made to the hospital decreased by $23 \%$. Furthermore, access to the cataract pathway increased with $42 \%$. A significant gap, however, between actual and expected care delivery remained in the lean pathway. When all decision rules and service specifications would have been followed, the number of visits would have decreased by $40 \%$, and access to the cataract pathway would have increased by $76 \%$.

The number of one-stop preassessments nearly doubled in the lean pathway (table 1). A delivery gap was identified when nurses mentioned that the preassessment clinic was a shared resource: if no walk-in capacity was available, patients received preassessments by appointment $(n=254$, figure 2$)$.

The number of patients who did not revisit the hospital for formulating the surgical care plan increased by a factor of 5.6 (table 1). However, 148 (75\%) of the 198 ophthalmic screening appointments were not based on the lean pathway's decision rules (figure 2, result 3). Ophthalmologists told us that occasionally they ordered ophthalmic screening appointments to remain personal contact with their patients, as with the new review methods in the lean pathway, they would not see them anymore after surgery.

Six of 10 patients in the lean pathway received a telephone review (table 1). Cataract surgeons explained that most of the

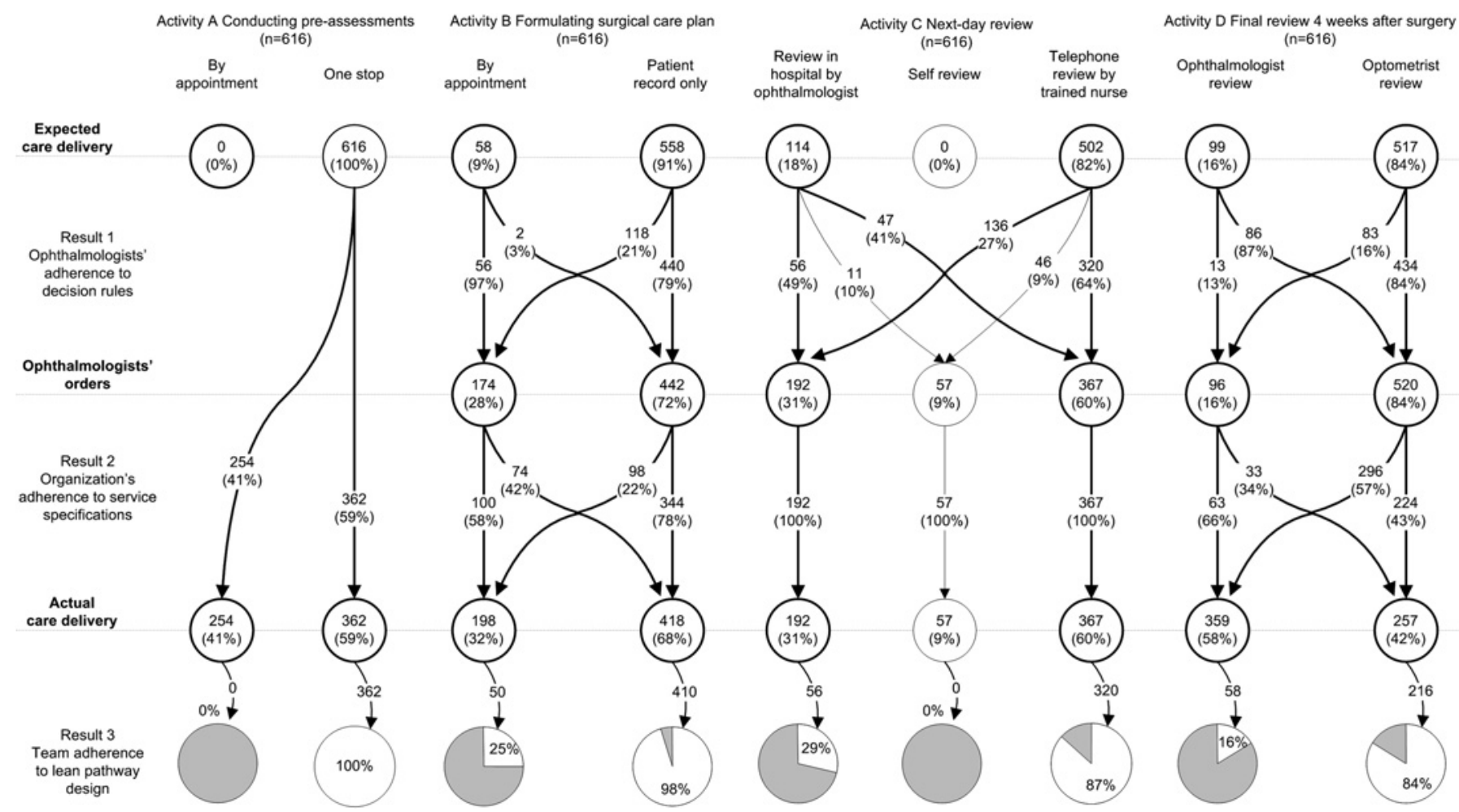

Figure 2 Adherence of the cataract care team to the lean pathway design. The 616 patients were allocated to traditional or new care alternatives according to (1) decision rules and service specifications, as stated in the lean pathway design, that is, expected care delivery; (2) ophthalmologist's orders, as registered in the patient records; and (3) actual care delivery. Traditional care alternatives: left side; new care alternatives: right side. In result 3: grey=delivery gap, that is, difference between expected and actual care delivery. 
Table 1 Efficacy and efficiency of the lean cataract pathway

\begin{tabular}{|c|c|c|c|c|}
\hline & $\begin{array}{l}\text { Traditional pathway } \\
\mathrm{n}=591\end{array}$ & $\begin{array}{l}\text { Lean pathway } \\
n=616\end{array}$ & p Value †† & p Value $\ddagger \ddagger$ \\
\hline \multicolumn{5}{|l|}{ Efficacy } \\
\hline A. One-stop preassessments & & & $<0.001 \neq$ & $<0.001 \S$ \\
\hline Expected care delivery* & NA & $616(100.0 \%)$ & & \\
\hline $\begin{array}{l}\text { B. Formulating surgical care plan using } \\
\text { the patient record only }\end{array}$ & & & $<0.001 \ddagger$ & $<0.001 \S$ \\
\hline C. Next-day telephone review & & & $<0.001 \neq$ & $<0.001 \S$ \\
\hline Actual care delivery* & $0(0 \%)$ & 367 (59.5\%) & & \\
\hline Expected care delivery* & NA & $502(81.5 \%)$ & & \\
\hline D. Final review by an optometrist & & & $<0.001 \neq$ & $<0.001 \S$ \\
\hline Actual care delivery* & $0(0 \%)$ & $257(41.7 \%)$ & & \\
\hline Expected care delivery* & NA & $517(83.9 \%)$ & & \\
\hline $\begin{array}{l}\text { 2. Amount of ophthalmologist's time } \\
\text { spent per patient in minutes }\end{array}$ & & & $<0.0019$ & $<0.001^{* *}$ \\
\hline Actual care delivery $\dagger$ & $48.2(2.2)$ & $35.3(6.7)$ & & \\
\hline Expected care delivery $\dagger$ & NA & $28.6(6.7)$ & & \\
\hline $\begin{array}{l}\text { 3. No of patients treated, related to } \\
\text { ophthalmologist's time needed to treat } \\
\text { one patient in traditional pathway }\end{array}$ & & & $<0.001 \uparrow$ & $<0.001^{* *}$ \\
\hline Actual care delivery $\dagger$ & $1.00(0.0)$ & $1.42(0.3)$ & & \\
\hline Expected care delivery $\dagger$ & NA & $1.76(0.3)$ & & \\
\hline
\end{tabular}

Actual care delivery in the lean pathway (2007) is compared with (1) actual care delivery in the traditional pathway (2004) and with (2) expected care delivery in the lean pathway, that is, care according to decision rules and service specifications, as stated in the lean pathway design.

${ }^{*}$ Number and percentage; †Mean with SD; $\ddagger \chi^{2} ; \S M c N e m a r ; ~ q I n d e p e n d e n t-s a m p l e s t$ test; ${ }^{*}$ Paired-samples $t$ test; $† \dagger p$ Value of statistical testing between actual care delivery in the traditional pathway and actual care delivery in the lean pathway; $\neq \neq p$ Value of statistical testing between actual care delivery and expected care delivery in the lean pathway;

NA, not applicable.

136 of 502 patients who were expected to receive a telephone review (figure 2, result 1 ), received an in-hospital review because of the medical training programme for residents. Furthermore, nurses remarked that ophthalmologists ordered the 57 self reviews, that is, reviews by patients themselves, mainly during Friday surgery sessions, because on Saturdays no nurses were available to conduct telephone reviews.

Despite the increase in optometrist reviews with a factor of 4.2, we would have expected an increase with a factor of 8.4 (Table 1). Ophthalmologists mentioned that decision rules for final review were not highly specified, leaving room for individual interpretation what review method was most appropriate for each patient (figure 2, result 1). Administrative staff told us that three information transfers were needed before they received information for scheduling the final review and that they only received orders for ophthalmologist review. If no order was received, either someone had forgotten to pass along the information ( $\mathrm{n}=33$, figure 2 , result 2 ) or an optometrist review was ordered. Furthermore, optometrists were a shared resource. If optometrist capacity was available, they booked an optometrist review. If not $(n=296$, figure 2 , result 2$)$, they booked an ophthalmologist review.

\section{DISCUSSION}

Efficiency significantly improved when the lean cataract pathway was applied compared with when the traditional pathway was applied. More importantly however, a significant gap between actual and expected care delivery remained. Efficacy might have improved if healthcare staff adhered more strictly to the lean pathway design. The main reasons we presently found that caused delivery gaps were ignoring decision rules, indirect or ambiguous communication, and allocation of shared resources.

To start closing the gap, we feel that clinicians first need to specify and then consent to their own decision rules. This can be challenging, as clinicians have a tendency to overpass written rules. ${ }^{33}$ The results of our study illustrated that, for several reasons, behaviour of ophthalmologists deviated from decision rules (eg, they missed contact with their patients or deemed their decision was more appropriate for the specific situation). Presenting the deviation we found may rationalise discussions on behaviour in medical decision-making.

Second, healthcare staff must be empowered to deliver care that conforms to specifications. Design of the pathway should make it easy for care professionals to comply with best practices, given their high level of workload in a lean pathway. ${ }^{34}$ In the present study, we observed that applying ambiguous service specifications such as 'schedule an optometrist final review, unless you receive an order for an ophthalmologist review' could not guarantee that the requested review was scheduled. We observed that direct communication (eg, between ophthalmologists ordering next-day reviews and nurses scheduling next-day reviews) resulted in perfect follow-up of ophthalmologist's decisions.

Third, to prevent extra visits (eg, for preassessments) or delivering care alternatives other than those ordered (eg, optometrist reviews), resources have to be available when needed. We found that allocation of shared resources hindered this synchronisation of supply and demand. However, enough manpower and patients will be needed to justify dedication of expensive resources to one pathway. ${ }^{35}$ 
The results of this study show that pathway designs with agreed-on decision rules and direct and unambiguous communication support healthcare staff to narrow the gap between expected and actual service delivery. The Rotterdam Eye Hospital recently integrated these concepts in their lean pathway design. Feedback on realised efficacy and efficiency supported the commitment of the cataract team to obtain results and pursue their goals.

In conclusion, we have reported that a lean pathway can realise significant improvements and still have a significant gap between expected and actual care delivery. Therefore, the challenge for healthcare teams is not just to improve care delivery by using lean pathways as opposed to using traditional pathways, but also to strive for optimal performance by consistently measuring and meeting easy-to-follow specifications.

Acknowledgements The authors thank NJ Reus (Rotterdam Eye Hospital) for his helpful comments on the manuscript.

Funding The Rotterdam Eye Hospital Research Foundation.

Competing interests None.

Ethics approval Ethics approval was provided by the Institutional Human Experimentation Committee of the Erasmus Medical Centre Rotterdam.

Provenance and peer review Not commissioned; externally peer reviewed.

\section{REFERENCES}

1. World Health Organization. Prevention of blindness and visual impairment. http:// www.who.int/mediacentre/factsheets/fs282/en/index.html. November 2004 (cited 14 Apr 2009).

2. Desai P, Minassian DC, Reidy A. National cataract surgery survey 1997-8: a report of the results of the clinical outcomes. Br J Ophthalmol 1999;83:1336-40.

3. Klaver CC, Wolfs RC, Vingerling JR, et al. Age-specific prevalence and causes of blindness and visual impairment in an older population: the Rotterdam Study. Arch Ophthalmol 1998;116:653-8.

4. The Royal College of Ophthalmologists. Cataract surgery guidelines. London: The Royal College of Ophthalmologists, 2004. http://www.rcophth.ac.uk/docs/ publications/published-guidelines/FinalVersionGuidelinesApril2007Updated. (accessed Apr 2009).

5. Hendrikse F, La Heij EC. Neemt het aantal mensen met gezichtsstoornissen toe of af? In: Volksgezondheid Toekomst Verkenning, Nationaal Kompas Volksgezondheid. (In Dutch). Bilthoven: RIVM, 2003. http://www.rivm.nl/vtv/object document/ 01144n17763.html (accessed Dec 2006)

6. Gogate PM. Small incision cataract surgery: Complications and mini-review. Indian J Ophthalmol 2009;57:45-9.

7. NHS Institute for Innovation and Improvement. Focus on: cataracts, best practice guidance, http://www.institute.nhs.uk. May 2008 (cited 14 Apr 2009).

8. Levitt T. Production-line approach to service. Harv Bus Rev 1972;50:41-52.

9. Ohno T. Toyota Production System, beyond large-scale production. New York: Productivity Press, 1988:8-15.

10. Womack JP, Jones TD. From lean production to the lean enterprise. Harv Bus Rev 1994:72:93-103.
11. Spear SJ. Decoding the DNA of the Toyota Production System. Harv Bus Rev 1999;77:96-106.

12. Institute of Healthcare Improvement. Going lean in health care (white paper). Cambridge, MA: Institute of Healthcare Improvement, 2005.

13. Bowen DE, Youngdahl WE. 'Lean' service: in defense of a production-line approach International Journal of Service Industry Management 1998;9:207-25.

14. Endsley S, Magill MK, Godfrey MM. Creating a lean practice. Fam Pract Manag 2006;13:34-8.

15. Young T, Brailsford S, Connell $C$, et al. Using industrial processes to improve patient care. BMJ 2004;328:162-4

16. Thompson DN, Wolf GA, Spear SJ. Driving improvement in patient care. J Nurs Adm 2003:33:585-95.

17. Spear SJ. Fixing healthcare from the inside: teaching residents to heal broken delivery processes as they heal sick patients. Acad Med 2006;81:s144-9.

18. Institute of Medicine. Crossing the quality chasm, a new health system for the 21 st century. USA: National Academy Press, 2001:23-38.

19. Spear SJ. Fixing health care from the inside, today. Harv Bus Rev 2005:83:78-91.

20. Parasuraman A, Zeithaml VA, Berry LL. A conceptual model of service quality and its implications for future research. J Mark 1985;49:41-50.

21. Murray MM, Berwick DM. Advanced access, reducing waiting and delays in primary care. JAMA 2003;289:1035-40.

22. King DL, Ben-Tovim DI, Bassham J. Redesigning emergency department patient flows: Application of Lean Thinking to health care. Emerg Med Australas 2006;18:391-7.

23. Bahensky JA, Roe J, Bolton R. Lean sigma-will it work for healthcare? J Healthc Inf Manag 2005;19:39-44.

24. Jimmerson C, Weber D, Sobek DK. Reducing waste and errors: piloting lean principles at Intermountain Healthcare. Jt Comm J Qual Patient Saf 2005;31:249-57

25. NHS Executive. Action on cataracts, good practice guidance. London: Department of Health, 2000. http://www.dh.gov.uk/prod consum dh/groups/dh digitalassets/ @dh/@en/documents/digitalasset/dh_401 (accessed_Apr 2009).

26. Tinley CG, Frost A, Hakin KN, et al. Is visual outcome compromised when next day review is omitted after phacoemulsification surgery? A randomised control trial. $\mathrm{Br} J$ Ophthalmol 2003;87:1350-5.

27. Mandal K, Dodds SG, Hildreth A, et al. Comparative study of first-day postoperative cataract review methods. J Cataract Refract Surg 2004:30:1966-71.

28. Herbert EN, Gibbons $\mathrm{H}$, Bell J, et al. Complications of phacoemulsification on the first postoperative day: can follow-up be safely changed? J Cataract Refract Surg 1999;25:985-8.

29. Booth A, Walters G, Cassels-Brown A, et al. Shared care postoperative management of cataract patients. Br J Ophthalmol 1998;82:332.

30. Revicki DA, Poe ML. Quality of care in cataract surgery cases experiencing postoperative complications with co-managed care. J Am Optom Assoc 1995:66:268-73

31. Kirkwood BJ, Pesudovs K, Latimer $P$, et al. The efficacy of a nurse-led preoperative cataract assessment and postoperative care clinic. Med J Aust 2006;184:278-81.

32. Silverman D. Interpreting qualitative data, methods for analysing talk, text and interaction. London: SAGE Publications, 2005:122-4.

33. McDonald R, Waring J, Harrison S, et al. Rules and guidelines in clinical practice: a qualitative study in operating theatres of doctors' and nurses' views. Qual Saf Health Care 2005:14:290-4.

34. Gurses AP, Seidl KL, Vaidya V, et al. Systems ambiguity and guideline compliance: a qualitative study of how intensive care units follow evidence-based guidelines to reduce healthcare-associated infections. Qual Saf Health Care 2008:17:351-9.

35. Vera A, Kuntz L. Process-based organization design and hospital efficiency. Health Care Manage Rev 2007;32:55-65. 